\title{
TRANSPARÊNCIA TRIBUTÁRIA E EFICIÊNCIA ARRECADATÓRIA: ANÁLISE DE DADOS EMPÍRICOS
}

\author{
TAX TRANSPARENCY AND TAX COLLECTION EFFICIENCY: ANALYSIS OF EMPIRICAL \\ DATA
}

\section{Gustavo Vettorato}

Advogado, mestre em Direito Constitucional e Sociedade (IDP), especialista em Direito Tributário (IBET e UNIRONDON) e Direito Constitucional (IDP), professor voluntário da Universidade Federal de Mato Grosso (UFMT), ex-conselheiro do Conselho Administrativo de Recursos Fiscais do Ministério da Fazenda (CARF/MF),

E-mail: gustavo.vettorato@gmail.com

\section{José Roberto Rodrigues Afonso}

Mini Cv - Economista, pós-doutorando no Instituto Superior de Ciências Sociais e Políticas da Universidade de Lisboa, doutor em Desenvolvimento Econômico (UEC), mestre em Economia da Indústria e da Tecnologia (UFRJ), pesquisador do IBRE/FGB e professor do Instituto Brasiliense de Direito Público.

E-mail: zeroberto@joserobertoafonso.com.br

\section{Luciano Felício Fuck}

Advogado, doutor em Direito Tributário (USP), mestre em Direito (LL. M. Eur), professor no Instituto Brasiliense de Direito Público.

E-mail lucianofelicio@gmail.com.

Recebido em: 01/04/2020

Aprovado em: 14/01/2021

RESUMO: Busca-se a confirmação da hipótese de que há relação entre transparência tributária e a eficiência arrecatória tanto em revisão bibliográfica quanto por dados empíricos (análise quantitativa e qualitativa), bem como a possibilidade de sua medição. Ao questionar qual seria a relação entre transparência e eficiência, em especial para o direito, partiu-se para análise pragmática, que teve como base uma pesquisa empírica com Administrações Tributárias Federal e Estaduais (escolhidas aleatoriamente) e sua relação com os contribuintes, analisando os comportamentos dos contribuintes e agentes fiscais em situações de maior ou menor opacidade tributária. Observou-se o confronto entre os índices de transparência do contencioso administrativo tributário e as quantidades de lançamentos de ofício em situações de erro/omissão/sonegação lavrados contra os contribuintes nos períodos de 2013 a 2016, o que apontou para indícios dessa relação.

Palavras-chave: Transparência tributária. Custos de transação. Eficiência arrecadatória. Comportamento do contribuinte. Comportamento do fisco. Análise de dados.

ABSTRACT: It seeks to confirm the hypothesis that there is a relationship between tax 
transparency and collection efficiency both in bibliographic review and in empirical data (quantitative and qualitative analysis), as well as the possibility of measuring it. When questioning the relationship between transparency and efficiency, especially for law, it started with a pragmatic analysis, which was based on an empirical research with Federal and State Tax Administrations (chosen at random) and their relationship with taxpayers, analyzing behaviors taxpayers and tax agents in situations of greater or lesser tax opacity. There was a confrontation between the transparency indexes of the administrative tax litigation and the amounts of tax assessment by the authority in situations of error/omission/evasion against taxpayers in the periods from 2013 to 2016, which pointed to signs of this relationship.

Keywords: Tax transparency. Transaction Costs. Collection efficiency. Taxpayer behavior. Tax behavior. Data analysis.

SUMÁRIO: Introdução; 1. Noções básicas sobre da transparência tributária e eficiência arrecadatória; 2. A análise de dados qualitativos e quantitativos; 2.1. Notas iniciais; 2.2. Comparações de lançamentos de ofício da União e o índice de transparência do contencioso tributário; 2.3. Comparações de lançamentos de ofício dos estados (SP, SC, PE e PR) e o índice de transparência do contencioso tributário; 2.4. Observações quanto às análises de dados de lançamentos de ofício e transparência tributária; Conclusão.

\section{INTRODUÇÃO}

O presente artigo é extraído de parte da pesquisa feita para dissertação para aprovação e conferência do grau de mestre, apresentada em 2019, envolvendo os seguintes temas transparência tributária, custos de transação tributários e eficiência arrecadatória. Entre os objetivos da pesquisa está a confirmação da hipótese que há relação entre transparência tributária (clareza dos atos e entendimentos do Fisco perante o contribuinte) e eficiência arrecadatória (otimização dos custos e resultados da arrecadação), bem como que aplicação da transparência tributária afeta a constituição do crédito tributário e os custos de conformidade do contribuinte (e de arrecadação).

O artigo é dividido em duas partes principais: resumo da revisão bibliográfica realizada (noções básicas) e análise de empírica do confronto de lançamentos tributários de ofício e os índices de transparência do contencioso administrativo.

No que tange parte análise empírica da pesquisa, buscou-se confirmar a hipótese de que há relação entre transparência tributária e eficiência arrecadatória, bem como da possibilidade de ser uma relação quantificável.

Como índice de transparência tributária utilizou-se o índice de transparência do contencioso tributário, por ausência de outros índices que quantificariam níveis de transparência da área tributária, sendo a transparência do contencioso administrativo o mais próximo do pretendido. Tais dados foram obtidos das pesquisas realizadas pelo Núcleo de Estudos Fiscais da Fundação Getúlio Vargas de São Paulo (NEF/FGV), que incluem os anos de 2013 a 2016 (únicos publicados). A pesquisa do NEF/FGV abrange todos os Estados-Membros, Distrito Federal e União (COELHO, 2017).

Os índices de transparência seriam confrontados com os quantitativos de lançamentos de lançamentos tributários de ofício (sobre erros e infrações dos contribuintes) no mesmo período da pesquisa do NEF. Foi considerado que os lançamentos tributários de ofício são os atos fiscais quantificáveis mais próximos da ocorrência do fato gerador, entendida como o momento da tomada de decisão tributária do contribuinte.

Para formação de um banco de dados referentes aos lançamento tributários de oficio, foram selecionados aleatoriamente nove Secretarias de Estado de Fazenda, as quais receberam um questionário solicitando os volumes e valores totais de lançamentos tributários de ofício de ICMS 
e acréscimos legais, realizados entre o período de 2013 e 2017 (na esperança da divulgação do índice de transparência pelo NEF/FGV quanto ao último período antes do final da pesquisa), sob o fundamento da Lei de Acesso à Informação. O motivo da limitação se deu pelo volume de dados que poderia ser enorme, limitada pelo tempo disponível para pesquisa. Os protocolos dos pedidos de informações foram feitos em fevereiro de 2018, contudo, até maio de 2019, somente seis unidades federativas responderam. Destes somente quatro forneceram dados que puderam ser analisados e confrontados (Paraná, Pernambuco, Santa Catarina e São Paulo).

Quanto aos dados da União, os períodos pesquisados também foram 2013 a 2016, referentes aos lançamentos de ofício do Imposto sobre a Renda de Pessoas Físicas. Os dados da União foram obtidos dos Planos Anuais de Fiscalização da Secretaria da Receita Federal do Brasil (BRASIL, 2015, 2017), que são anualmente disponibilizados no site do órgão.

Com base desses dados, foi possível realizar a análise de confronto dos períodos de 2013 a 2016, que se apresenta neste artigo.

Dentre outros pontos ${ }^{1}$, analisou-se o comportamento dos contribuintes e dos agentes fiscais pelo confronto de quantitativos dos lançamentos tributários de ofício e índices de transparência do contencioso administrativo tributário.

\section{NOÇÕES BÁSICAS SOBRE TRANSPARÊNCIA TRIBUTÁRIA E EFICIÊNCIA ARRECADATÓRIA}

É necessária a densificação clara das normas tributárias ao contribuinte, devido a sua importância como intérprete e aplicador do Direito Tributário. Especifica-se a garantia de transparência da Administração Tributária, estabelecida neste trabalho como transparência tributária. Suas fontes constitucionais seriam oriundas das garantias de liberdade de acesso às informações e de publicidade dos seus atos aos cidadãos, com base nos arts. $5^{\circ}$, IV, XIV, XXXIII, XXXIV, b, e LX, e 37, $\S \S 1^{\circ}$ e $3^{\circ}$, II, da Constituição Federal de 1988, o que garantiria, em todos os procedimentos administrativos tributários, tanto do contencioso quanto dos demais de natureza interpretativa, o conhecimento geral de suas decisões e respostas às consultas dos contribuintes e seus setores internos, indiferentemente do destinatário original (SANTI, 2014).

Entretanto, encontra resistência por parte do Fisco, em geral, sob escusa genérica de sigilo fiscal, razão pela qual é importante indagar se a Fazenda Pública disponibiliza de forma rápida e ampla os seus entendimentos sobre a aplicação da legislação tributária, apesar das críticas doutrinárias (SANTI, 2014).

Nessa linha, é necessária a utilização de duas das principais correntes da filosofia moral aplicadas ao direito: Deontologia e Consequencialismo. A primeira linha entende que a ação humana é considerada moralmente correta quando realizada em obediência rígida de princípios e regras que refletem valores morais, isso aplicável à prática jurídica. Já, o Consequencialismo, apesar de considerar os valores e ideais substantivos como guias da ação humana, dá ênfase aos resultados e fins pretendidos pelo agente, assim um ato somente seria moralmente correto quando as suas consequências pretendidas ou reais sejam mais benéficas à sociedade que outras opções. Isoladamente, nenhuma das duas correntes permite a análise das hipóteses propostas. Por isso, não se adota exclusivamente nenhuma delas, pois ambas podem dividir o mesmo espaço, inclusive porque, ironicamente, pode se entender a moral deontológica como fruto evolucionário da repetição e depuração da experiência humana com seus atos que geraram consequências benéficas à sociedade. (CARVALHO, C., 2018).

\footnotetext{
${ }^{1} \mathrm{Na}$ pesquisa empírica da dissertação, também abordou-se a evolução do estoque de créditos tributários inscritos em dívida ativa da União, em relação aos procedimentos de arrecadação realizados pela Procuradoria-Geral do Estado e ao PIB brasileiro; e a experiência internacional com casos relatados pela OCDE (2011) e outros autores, para a transformação de uma relação não cooperativa em cooperativa, os quais têm pontos em comum, conforme Richard Bird (BIRD, 2010).
} 
O valor de transparência seria fruto de repetição de atos que gerariam resultados proveitosos a toda sociedade, o seu emprego seria a utilização de consequências já experimentadas e entendidas como benéficas, gerando norma de conduta pret'a porte. Contudo, a aplicação de valores como normas acabam por enfrentar a alteração da realidade, para a qual aqueles não teriam resposta pronta em vários momentos. Logo, o estudo das consequências na tomada de decisão torna-se um instrumento viável. Por isso, o artigo não terá abordagem exclusivista.

Dessa forma, se estabelece que a transparência, tanto como valor quanto ato que gera consequências, sendo fundamental para fins de controle e limitação da Administração Pública. $\mathrm{O}$ dever transparência tributária será entendido como dever clareza e precisão da legislação e entendimentos tributários, necessária para a própria eficiência tributária. Isso, em razão de que a segurança jurídica, em uma realidade de riscos, exige a correta interpretação e aplicação da norma tributária, possível quando o aplicador do direito tiver cognição plena da legislação tributária. A transparência seria a baliza da imparcialidade e da confiança do contribuinte perante o Fisco, com fins de proteção às expectativas legítimas dos envolvidos (SOUZA, 2012). O contrário seria a opacidade jurídica (ou opacidade do jurídico) conceito cunhado por Carlos Maria Carcova (1998), pois o direito atua na vida social, como uma partitura ou livreto que não seria totalmente conhecido ou compreendido pelos atores em cena, que realizaram rituais, imitam condutas, com poиса ou nenhuma percepção de seus significados e alcances.

A não disponibilização geral dos entendimentos do Fisco sobre a norma tributária constitui-se em opacidade jurídica, causadora de alienação, litigiosidade, insegurança jurídica, assimetria de conhecimento, desigualdade no tratamento e ineficiência administrativa e arrecadatória. Fatos que são contrários aos princípios democráticos e à pacificação de condutas a serem adotadas pelo contribuinte, oriundos não só do texto legal, mas também da interpretação corriqueira dos órgãos de julgamento e de consulta tributária (SANTI, 2014).

$\mathrm{O}$ ambiente de opacidade jurídico-tributária não estimula a conformidade. Tanto a experiência brasileira quanto a internacional têm verificado essas situações. Sinais do desestímulo à conformidade encontram-se em fatos como o estoque de dívida ativa aproximar-se a um terço do Produto Interno Bruto, em progressão superior ao de sua realização. Estudos da OCDE apontam como causa desse tipo de problema a desconfiança do contribuinte perante o Fisco, baseando-se apenas em ações repressivas (mandato-controle), o que amplia a opacidade e consequente litigiosidade ineficiente do sistema tributário (ALMEIDA, 2018).

Como premissa, está que a concretização da norma tributária se dá pela constituição do crédito tributário, tanto por autoconstituição (realizado pelo próprio contribuinte) como por lançamento fiscal (que é ato de ofício indiferentemente de sua classificação - art. 142 c/c 149, do CTN), colocada como a inserção, no mundo jurídico, da obrigação tributária oriunda da incidência da hipótese impositiva prevista na lei em sentido estrito, por instrumento legalmente adequado (CARVALHO, P., 2000). Na produção desse ato jurídico de concretização da norma tributária, pela constituição do crédito tributário ou no cumprimento de obrigações instrumentais, é que se vislumbra a relação e a importância do ato com a transparência.

$\mathrm{O}$ ato de constituição do crédito tributário é o ápice da conjunção de outros construtos normativos vindos dos mais diversos personagens ou intérpretes ${ }^{2}$. A interpretação dos signos dos textos legais gerará uma norma geral e abstrata e outra norma individual e concreta interdependentes do intérprete, em consonância com a Constituição (CARVALHO, P., 2000). A dinâmica de aplicação da norma tributária nada mais é do que uma relação simbiótica entre Contribuinte e Fisco, sendo que o ritmo e a fluidez da dinâmica dessas relações mútuas são tão proporcionais quanto às informações e instrumentos de interpretação disponibilizados ao contribuinte pelo Fisco e vice e versa. O contribuinte efetivamente assume as competências anteriormente privativas dos agentes fiscais (PIMENTEL, 2010). E a litigiosidade será decorrente

${ }^{2}$ O número de intérpretes da Constituição não é numerus clausus (HÄBERLE, 1996).

Revista de Direito Brasileira | Florianópolis, SC | v. 27 | n. 10 | p.92-111 | Set./Dez. 2020 
da relação jurídico-tributária na mesma proporção paradoxal, em um ambiente opaco sob a alegação de bem coletivo e sigilo, o Estado limita o nível de informações normativas do contribuinte.

A relevância da relação entre transparência e constituição do crédito tributário sobressaise com o fenômeno de transferência de deveres, custos e riscos de constituição do crédito tributário do Fisco ao contribuinte, cabendo ao contribuinte a interpretação e a aplicação das normas tributárias (SANTI, 2014).

Com a importância do contribuinte na constituição do crédito tributário, considerando que de forma geral a eficiência é uma relação de custo-benefício, assim, se transparência tributária é componente do custo, pode-se entender que ela também é um dos componentes da eficiência.

Ao tratar de custos Ronald Coase (2017) ressalta que as instituições são criadas para reduzir a insegurança social ou dos agentes do mercado. Quaisquer fatores de insegurança ou de desinformação serão componentes dos custos de transação do mercado, afetando a eficiência econômica. Com base em Coase e Calabresi, Paulo Caliendo (2009) expõe que os custos de transação do mercado incluem os custos de informação do ambiente institucional (regras do jogo), os quais são direcionados à redução de incertezas. O nível de opacidade do ambiente institucional será relacionado com o aumento ou a diminuição dos custos de transação conhecidos como custos de oportunidade, informação e decisão, e a necessidade de um novo arranjo institucional para alcançar a estabilidade de curto prazo. E, em um mundo real, toda transação tem custos, nem sempre vinculados à direta produção destes (COASE, 2017).

O contribuinte tende a agregar, dentro de sua atividade (firma) ou fora, agentes (contadores, advogados e outros especialistas) e procedimentos para redução de riscos e incertezas para manutenção de sua conformidade fiscal, havendo agregação de custo para isso. Luciana Ibiapina Lira Aguiar observa que o custo de conformidade fiscal não inclui apenas o pagamento de tributos, mas também os gastos com o cumprimento das obrigações acessórias, que envolvem a contratação e a qualificação de profissionais, prestadores de equipes de apoio e consultoria e equipamentos (hardwares e softwares - CARVALHO, P., 2018). Eles tendem a aumentar para reduzir a não conformidade fiscal involuntária natural em um ambiente de pouca transparência tributária (SANTI, 2014). Contudo, tais custos são refletidos também ao Estado que, além de transferi-los ao contribuinte, assume custos com a ausência de conformidade voluntária (BERTOLUCCI, 2006). Com o aumento da importância dos contribuintes na relação jurídicotributária, a transparência tem maior influência nos custos de conformidade tributária e nos custos de arrecadação, que são divididos entre o Fisco e o contribuinte, em razão da relação com o seu fluxo de informações e percepções.

Assim, volta-se ao princípio da eficiência (art. 37 da CF/1988), mesmo em seu conteúdo deontológico, acaba por ter um claro conteúdo consequencialista, pois obriga o intérprete e o agente público a buscar o resultado real das ações com melhor custo-benefício (alocação ótima de recursos para maximização dos resultados). Nada é eficiente por princípio (acepção de origem), mas por consequência. A eficiência da Administração Pública vem do conhecimento dos recursos disponíveis para atingir de forma mais eficaz o bem social (LOPES, 1998). Logo, a relação de transparência e eficiência tem em seu escopo uma análise consequencialista (POSNER, 2007), mesmo que seja difícil a obtenção de dados e métodos de medição da eficiência ou da transparência.

Tanto Coase quanto Posner entendem que a eficiência tratar-se-ia um equilíbrio entre a disposição e a proporção de alocação de recursos para se obter a quantidade/qualidade do bem almejado. O equilíbrio seria a perfeita alocação de recursos para a maximização do bem almejado, mas deveria considerar a dinâmica de mercado, preferências, direito e outros. Mesmo que não totalmente adequada à análise de eficiência jurídica, entendem como superior a exposição de eficiência exposta por Nicholas Kaldor e John Hicks (Kaldor-Hicks). Nessa concepção de eficiência, consideram-se situações de prejuízo imediato com melhoria de resultados em longo prazo, bem como as situações de não voluntariedade, típico do Estado Fiscal, em que o contribuinte 
tem prejuízo imediato com tributação, mas a recompensa é realizada pela prestação de serviços públicos (POSNER, 2007). Ou seja, em sua versão de valor positivado (art. 37 da CF/1988), a eficiência teria grande carga instrumental, um meio para consecução de outros valores (CARVALHO, C., 2018).

Pode-se pensar a eficiência da Administração Tributária como uma busca de recursos públicos pela arrecadação de tributos com fins de garantir direitos fundamentais com menor geração de custos, tanto para o poder público quanto ao contribuinte. Isso representaria um caminho intermediário entre justiça tributária aliada à neutralidade tributária, em que os custos tributários afetem o menos o possível os custos de transações das instituições (CALIENDO, 2009). No caso, a melhor alocação de custos (internos e externos) da Administração Tributária com seu resultado, em razão do comportamento do contribuinte (MARTINS, 2008).

Todos os agentes envolvidos na relação jurídico-tributária têm algum objetivo que corresponderia a sua melhor alocação de recursos com vista à maximização de algo. Esse algo seria aquilo considerado como o bem de preferência do agente, influenciando a sua escolha de como agir, em especial na decisão jurídica. Em tese, no Direito Tributário, o contribuinte tem como preferência a maximização da economia fiscal; o agente fiscal, a autuação eficiente; e o julgador, pôr fim ao litígio alcançando a decisão justa (CARVALHO, C., 2018). Essas preferências devem ser consideradas, pois têm origens das mais diversas ordens (econômicas, morais, jurídicas, etc.), vindo o direito a ser elemento importante (não único) da tomada de decisão. Logo, como eficiência tratar-se-ia de elemento de maximização de algum bem que seja considerado desejável à sociedade de seu tempo e local, considerando o Direito como um de seus moduladores (CALIENDO, 2009).

$\mathrm{O}$ conhecimento do estado de coisas torna-se central na tomada de atos que buscam a maximização do bem público ou economia fiscal. Como posto por Joseph Stiglitz, a opacidade é geradora de assimetrias de conhecimento e, consequentemente, disparidade de várias naturezas entre os agentes da relação, que são diminuídas com a redução das áreas obscuras (STIGLITZ, 1999). A existência de um ambiente institucional transparente terá consequências nos custos de transação de mercado e espaços sem imposição tributária.

Dessa forma, para fins de continuidade, espera-se ter densificado minimamente conceitos necessários para a análise dos dados obtidos.

\section{A ANÁLISE DE DADOS QUALITATIVOS E QUANTITATIVOS}

\subsection{Notas iniciais}

Da revisão bibliográfica, já seria possível a indicação de confirmação da existência da relação entre os custos de conformidade e transparência tributária, consequentemente, também da hipótese de seu relacionamento com a eficiência arrecadatória. O mesmo pode ser vislumbrado pela pesquisa empírica, no caso da análise de dados quantitativos e qualitativos.

Como já apresentado: a eficiência arrecadatória pode ser maior, quanto maior a simplicidade e clareza do sistema. Para sua análise, confrontaram-se dados referentes à transparência tributária que se relacionassem com a arrecadação.

Buscaram-se elementos que compõem ou demonstrem a alocação ótima de recursos segundo a pretensão dos agentes envolvidos. A eficiência de arrecadação pode ser refletida pela maximização pretendida pelo agente fiscal: o lançamento eficiente. A avaliação de eficiência arrecadatória mais comum é a análise de desempenho tributário como da carga tributária (arrecadação dividida pelo Produto Interno Bruto) no exercício financeiro (AFONSO e CASTRO, 2017). Todavia, tal avaliação foi pobre para os fins do trabalho, pois desconsidera fatores como quantidade de lançamentos de ofício, políticas tributárias e outros elementos importantes para a avaliação. Assim: quais seriam os indicadores mais adequados à análise, com base nos dados disponíveis? 
Entre os possíveis indicadores, adotaram-se os seguintes: o volume (quantitativo) e valores de lançamentos de ofício (em caso de infrações) realizados nos exercícios de 2013 a 2016 pelas administrações tributárias. Tais indicadores são mais próximos da ocorrência do fato gerador e constituição do crédito tributário pelo lançamento de ofício em casos de infrações. A lavratura do lançamento ocorre pelo conflito entre o contribuinte (quando, por desconhecimento ou intencionalmente, não realiza a "autoconstituição" ou os procedimentos adequados para a constituição do crédito tributário) e o Fisco, o qual se vê na situação de constituir de ofício o crédito tributário (art. 142 do CTN). Enquanto, caso fosse trabalhado apenas com a efetiva arrecadação, os dados estariam muito mais poluídos com fatores variáveis e distantes temporalmente da decisão do contribuinte, a exemplo do lapso entre a ocorrência do fato gerador e a influência de possíveis alterações de política tributária que incluem programas de regularização com anistias ou remissões.

Os dados dos lançamentos de ofício foram comparados com os índices de transparência do contencioso administrativo tributário apurados pelo NEF/FGV-SP, entre 2013 e 2016 (COELHO, 2017). A pesquisa do NEF/FGV-SP é uma das únicas fontes de aferição de um dos aspectos da transparência tributária, contudo dizem respeito a uma relevante parte vinculada à interpretação da norma tributária, que contém o efeito prático semelhante ao da jurisprudência no Poder Judiciário.

Nas comparações feitas com base na Fazenda Nacional, utilizaram-se as quantidades totais de autuações realizadas pelos agentes fiscalizadores da Secretaria da Receita Federal do Brasil (SRFB), ou seja, lançamentos de ofício (autos de infração). Os valores foram obtidos nos Planos Anuais de Fiscalização da Receita Federal do Brasil, que contêm séries históricas de lançamentos de ofício lavrados entre os exercícios de 2013 e 2016 (BRASIL, 2015, 2017), em comparação com os índices auferidos pelo NEF/FGV com base nos anos de 2013 a 2016 (COELHO, 2017).

$\mathrm{Na}$ coleta de dados dos Fiscos Estaduais, consideraram-se 9 (nove) Estados, escolhidos aleatoriamente, salvo o Estado de Mato Grosso em razão de ser o local de domicílio do dissente. Entre janeiro e fevereiro de 2018, foram realizados 9 (nove) pedidos às Secretarias de Estado de Fazenda, solicitando as quantidades e valores globais de lançamentos tributários de ofício (por infração) constituidores de créditos tributários de ICMS. Apenas 6 (seis) pedidos foram respondidos com alguma informação ao questionado, 3 (três) não responderam ou negaram acesso. As Secretarias de Estado de Fazenda de São Paulo, Santa Catarina, Paraná e Pernambuco enviaram dados quantitativos sobre os lançamentos de ofício de ICMS, valores lançados, e penalidades aplicadas, tudo referente aos anos de 2013 a 2017, de forma mais completa que os demais ${ }^{3}$. Como colocado na introdução, os dados do ano de 2017 foram solicitados às unidades fazendárias estaduais na esperança frustrada de publicação do índice de transparência do período pelo $\mathrm{NEF} / \mathrm{FGV}$.

\footnotetext{
3 Os pedidos de informações (questionário) tinham como a Lei n. 12.527/2017 (Lei de Acesso à Informação), direcionados a 9 (nove) Secretarias de Estado de Fazenda, mediante protocolo nos respectivos órgãos de transparência. Os estados que receberam os pedidos foram: São Paulo, Bahia, Minas Gerais, Mato Grosso, Pernambuco, Pará, Santa Catarina, Paraná, Distrito Federal. Em um primeiro teste de transparência, já se pode utilizar as respostas positivas ou negativas de cada uma das Unidades Federativas: (1) as unidades federativas que responderam positivamente enviando os dados solicitados: São Paulo, Paraná, Santa Catarina, e Pernambuco; (2) As unidades federativas que responderam parcialmente: Minas Gerais, Pará; (3) as unidades federativas que negaram ou NÃO responderam até a data de consolidação da dissertação: Mato Grosso, Bahia e Distrito Federal. Os respectivos pedidos, protocolos, respostas e dados fazem parte dos anexos à dissertação depositada no IDP. Em tempo, anote-se a pontuação no índice de transparência do contencioso administrativo tributário do NEF/FGV no ano de 2016 das Administrações Tributárias Estaduais que tiveram protocolizado os pedidos de informação, pois, salvo a Bahia (96 pontos), o Estado de Mato Grosso (8 pontos) e o Distrito Federal (11 pontos) estão entre as piores posições e não responderam nada do questionado, de outro lado os Estados de São Paulo (76 pontos), Pernambuco (54 pontos) e Santa Catarina (76 pontos) estão entre as melhores e demonstram interesse em apresentar os dados solicitados ou informaram a impossibilidade (COELHO, 2017).
} 


\subsection{Comparações de Lançamentos de Ofício da União e o Índice de Transparência do} Contencioso Tributário

No que tange às comparações dos dados oriundos da União, nos exercícios de 2013 a 2016, convida-se a leitura da tabela 2.2.a e gráfico 2.2.a, demonstradores da evolução da quantidade de lançamentos de ofício naquele período (BRASIL, 2015, 2017).

Tabela 2.2.a

\begin{tabular}{|c|c|c|c|c|}
\hline $\begin{array}{c}\text { Quantidade de Lançamentos de Ofício (Autuações) Realizados pela } \\
\text { SRFB }\end{array}$ \\
\hline Exercício & $\mathbf{2 0 1 3}$ & $\mathbf{2 0 1 4}$ & $\mathbf{2 0 1 5}$ & $\mathbf{2 0 1 6}$ \\
\hline Quantidade de Lançamentos & 329036 & 365832 & 277564 & 345941 \\
\hline Variação Com Ano Anterior & & $11 \%$ & $-24 \%$ & $25 \%$ \\
\hline
\end{tabular}

Fonte: Secretaria da Receita Federal do Brasil.

\section{Gráfico 2.2.a}

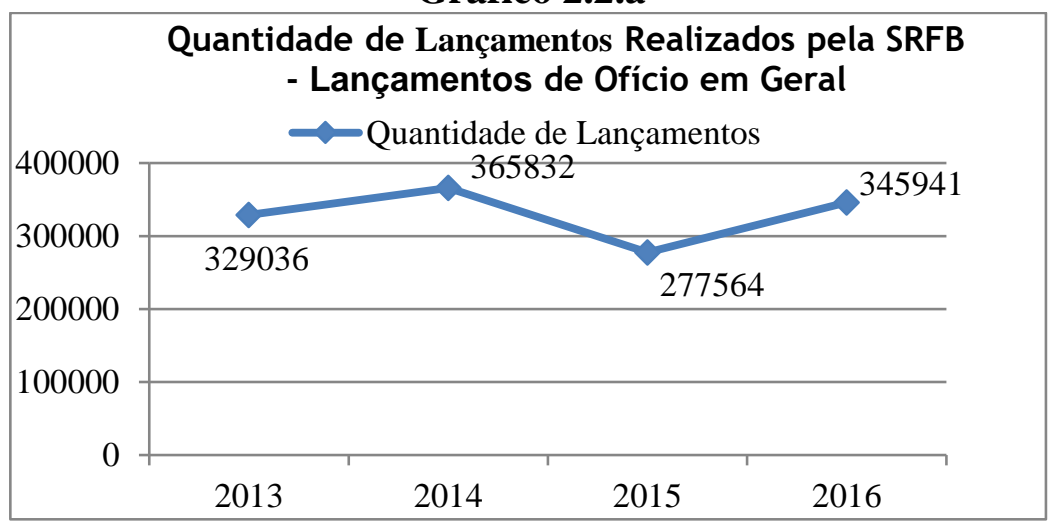

Fonte: Secretaria da Receita Federal do Brasil.

Observa-se que, nos períodos analisados, no ano de 2014, a atividade de lançamento de ofício atingiu o maior volume total de 365.832 lançamentos.

O gráfico 2.2.a acaba seguindo comportamento semelhante ao número de autuações (lançamento) realizadas às Pessoas Físicas. Note-se que os contribuintes pessoas físicas geralmente têm menor auxílio para realização dos procedimentos de autoconstituição do crédito tributário, bem como representam o maior volume de lançamentos de ofício (BRASIL, 2015, 2017). Isso é confirmado na tabela 2.2.b e gráfico 2.2.b:

Tabela 2.2.b

\begin{tabular}{|c|c|c|c|c|}
\hline \multicolumn{5}{|c|}{$\begin{array}{l}\text { Quantidade de Lançamentos de Ofício (Autuações) Realizados pela SRFB - } \\
\text { Pessoas Físicas }\end{array}$} \\
\hline Exercício & 2013 & 2014 & 2015 & 2016 \\
\hline Quantidade de Lançamentos & 312393 & 351534 & 268457 & 337084 \\
\hline Variação com Ano Anterior & & $13 \%$ & $-24 \%$ & $26 \%$ \\
\hline $\begin{array}{l}\text { Participação no Total de Lançamentos de } \\
\text { Ofício }\end{array}$ & $95 \%$ & $96 \%$ & $97 \%$ & $97 \%$ \\
\hline
\end{tabular}

Fonte: Secretaria da Receita Federal do Brasil. 
Gráfico 2.2.b

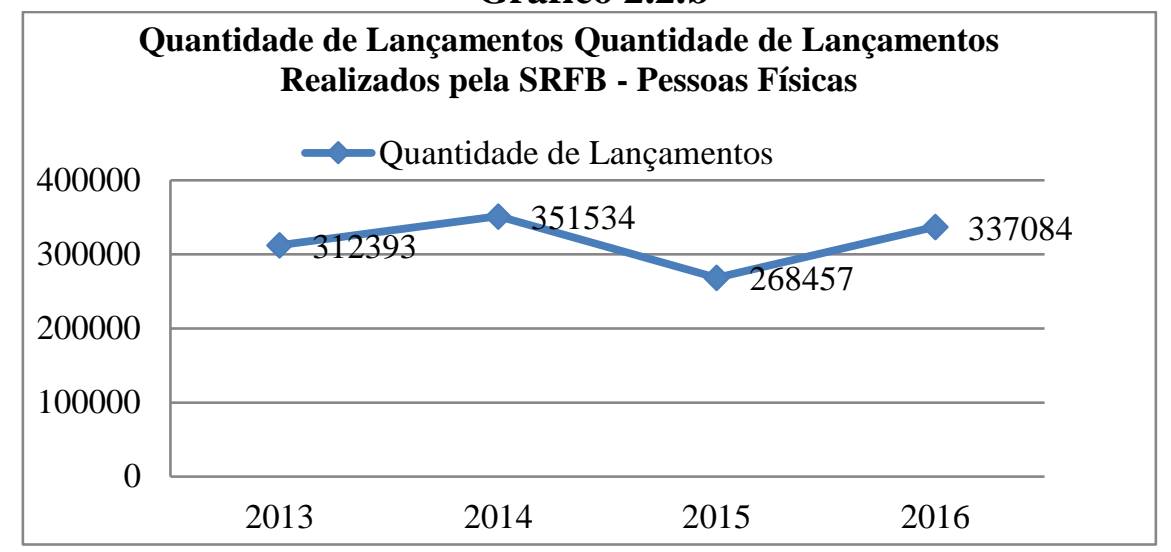

Fonte: Secretaria da Receita Federal do Brasil.

Quanto ao volume das autuações fiscais da União, pode-se dizer que a variação do volume decorre principalmente das autuações das pessoas físicas, mesmo que representem valores menores por cada lançamento individual.

A situação recebe destaque em relação ao objeto de pesquisa quando se contrastam os níveis de transparência do contencioso administrativo tributário da União, fornecidos pelo NEF/FGV (COELHO, 2017), nos mesmos períodos dos números anteriormente indicados referentes aos volumes de lançamento, conforme tabela 2.2.c e gráfico 2.2.c.

Tabela 2.2.c

\begin{tabular}{|l|r|r|r|r|}
\hline Nível de Transparência do Contencioso Administrativo Tributário da \\
União
\end{tabular}

Fonte: NEF/FGV-SP.

Gráfico 2.2.c

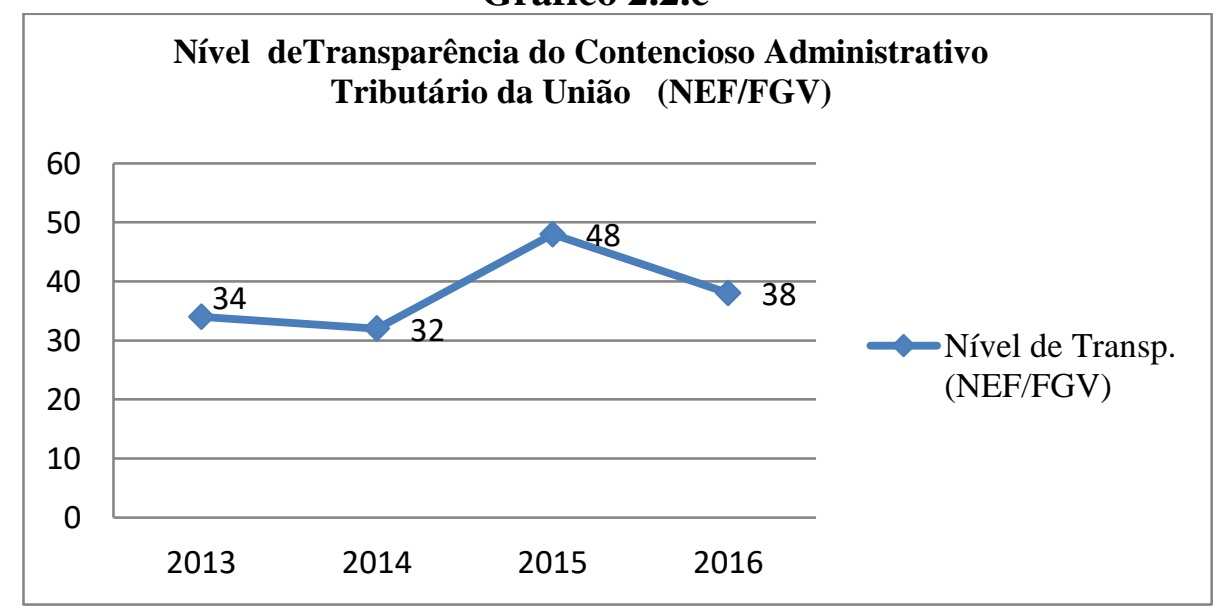

Fonte: NEF/FGV-SP.

Assim, após o confronto das tabelas e dos gráficos indicados anteriormente, a situação fica literalmente estranha ao confrontar tais dados em um mesmo plano apresentado no gráfico 2.2.d: 
Gráfico 2.2.d

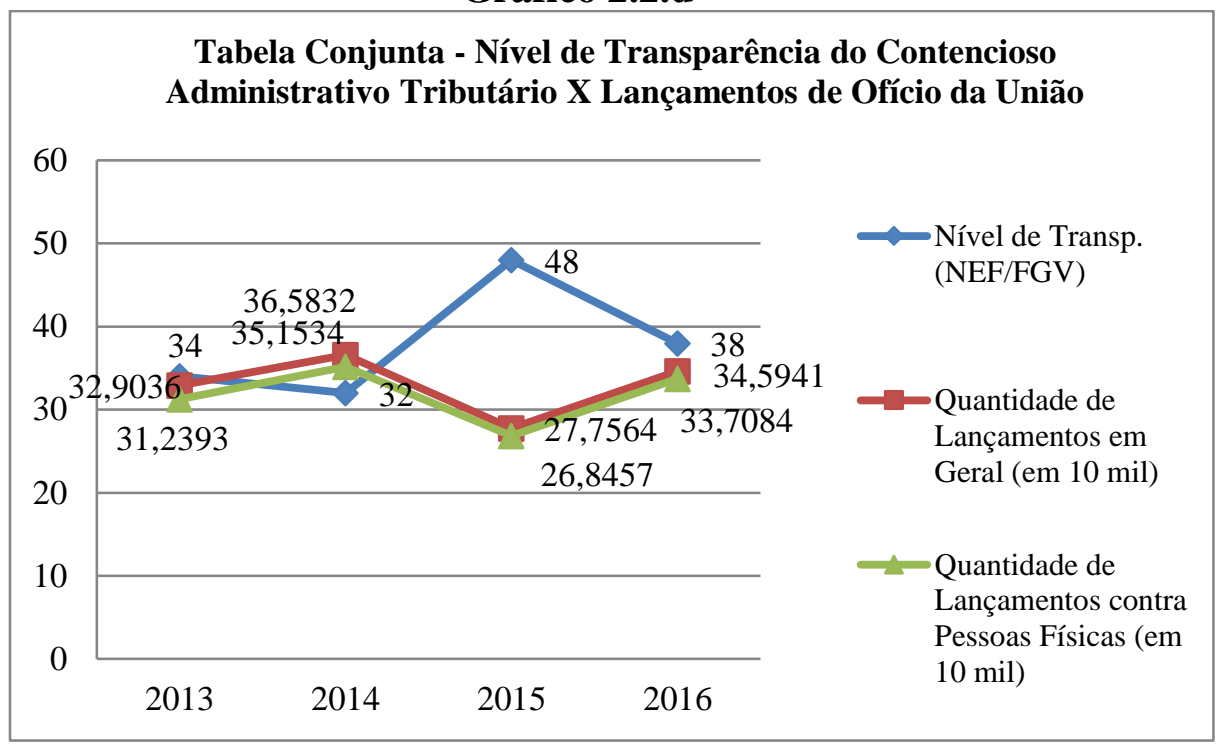

Fontes: NEF/FGV-SP e Secretaria da Receita Federal do Brasil.

Com base na análise dos dados compilados, existe um comportamento antagônico (ou espelhado) entre quantidade de lançamentos de ofício e nível de transparência do contencioso administrativo, acentuada nas autuações contra pessoas físicas.

Deve-se observar que a Declaração Anual de Ajuste do Imposto de Renda de Pessoa Física é preenchida por grande parcela de pessoas que não são profissionais da área tributária, sofrendo maiores reflexos da transparência, na forma de clareza e simplicidade de informações. No atual momento histórico, qualquer pessoa com acesso à rede mundial de computadores pode localizar inúmeras informações, inclusive conflituosas, o que aumenta a necessidade do Fisco de simplificar e amenizar o conflito de informações. Aparentemente, quando isso ocorre, os contribuintes com menor estrutura para conformidade são beneficiados.

\subsection{Comparações de lançamentos de ofício dos Estados (SP, SC, PE e PR) e o Índice de Transparência do Contencioso Tributário.}

Na esfera do Fisco Federal se assemelha ao que foi obtido dos dados dos Fiscos de São Paulo, Santa Catarina, Paraná e Pernambuco, que forneceram dados que possibilitaram o cruzamento entre quantidade de lançamentos de ofício e nível de transparência do contencioso administrativo tributário.

A escolha para coleta de dados foi pelos lançamentos de ofício oriundos da tributação estadual do ICMS, no período de 2013 a 2017, devido a sua participação na arrecadação tributária nacional. Entretanto, desde já se deve anotar que em razão da competência tributária estadual (art. 155, II, da CF/1988), não há uniformidade entre as unidades federativas, tanto quanto aos instrumentos de constituição do crédito tributário, obrigações instrumentais, e procedimentos de revisão. Os pedidos de informação realizados aos Fiscos Estaduais buscaram informações sobre lançamentos de ofício (obrigações principais e acessórias) e aplicação de multa, em valores brutos especificando apenas que deveriam ser de autuações realizadas por fiscais, excluindo-se os casos de valores constituídos por autolançamento. Santa Catarina e Pernambuco forneceram planilhas gerais de todos os lançamentos tributários, não informando se estavam com valores atualizados, nesse caso, foram separados apenas os lançamentos tributários reconhecidos como de ofício sobre o ICMS (autuações de infração). Já São Paulo e Paraná, foram claros em informar que os valores apresentados eram nominais, bem como vincularam os mesmos apenas a lançamentos efetivamente de ofícios de ICMS (autos de infração). Todos forneceram informações sobre as multas lançadas 
no período. As tabelas com a consolidação detalhada dos dados compilados estão em anexo da presente dissertação.

Deve-se observar que, devido ao aspecto subjetivo passivo da hipótese de incidência do ICMS, a quase absoluta maioria dos seus contribuintes são pessoas jurídicas e físicas que têm como atividade econômica habitual (ou profissional) a circulação de mercadorias e prestação de serviços de comunicação e transporte.

Relembre-se que Imposto sobre a Renda da Pessoa Física (IRPF) tem por característica a universalidade de sujeitos passivos, com procedimentos simplificados de constituição de seu crédito tributário, possibilitando ser realizado por qualquer cidadão. O ICMS é infinitamente mais complexo, tem como principais características a não cumulatividade e múltiplas realidades jurídicas variantes entre os Fiscos Estaduais, mas incide sobre pessoas habituadas ao comércio (em maioria dos casos). Os sujeitos passivos do ICMS geralmente têm custos de conformidade tributária maiores que os contribuintes do IRPF, para o cumprimento das obrigações instrumentais do tributo há a necessidade de um profissional contábil, no mínimo.

Esse estado de coisas indica que há alguma relação entre a arrecadação tributária e os custos de informação (do contribuinte e do Fisco), vinculados à transparência tributária mesmo sem uma quantificação clara. Mas, é possível averiguar indícios de que a relação possa existir, com efeitos à eficiência tributária.

O primeiro cruzamento realizado foi quanto ao número de lançamentos tributários de ofício de ICMS fornecidos pelos Estados, em comparação com os índices de transparência do contencioso tributário apurados pelo NEF/FGV (COELHO, 2017), nos anos de 2013 a 2016 (2017 não fora aferido pelo instituto de pesquisa). A comparação gerou os seguintes gráficos e tabelas:

\section{Gráfico/Tabela 2.3.a}

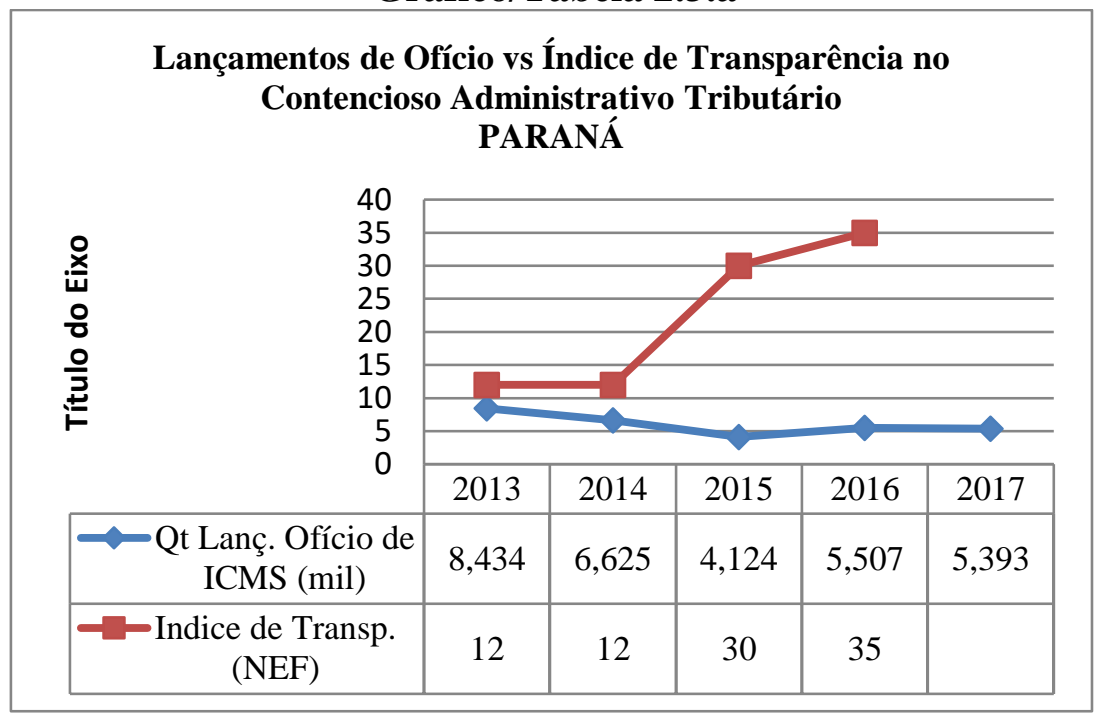

Fontes: NEF/FGV-SP e Secretaria de Estado de Fazenda do Paraná. 


\section{Gráfico/Tabela 2.3.b}

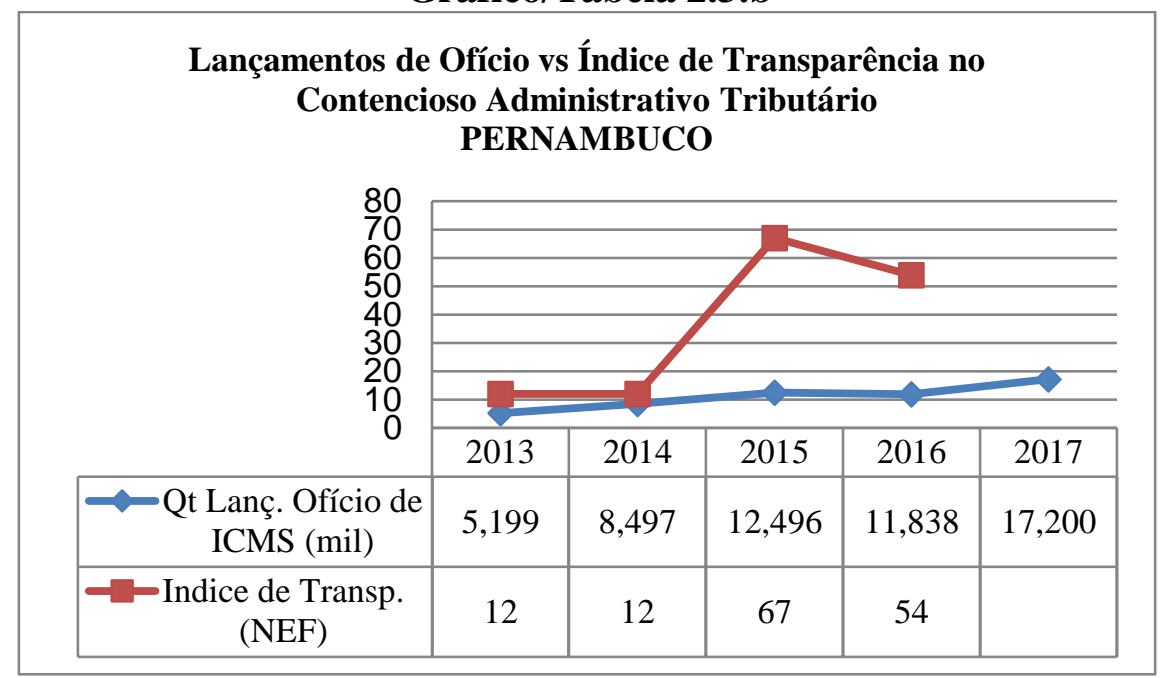

Fontes: NEF/FGV-SP e Secretaria de Estado de Fazenda de Pernambuco.

\section{Gráfico/Tabela 2.3.c}

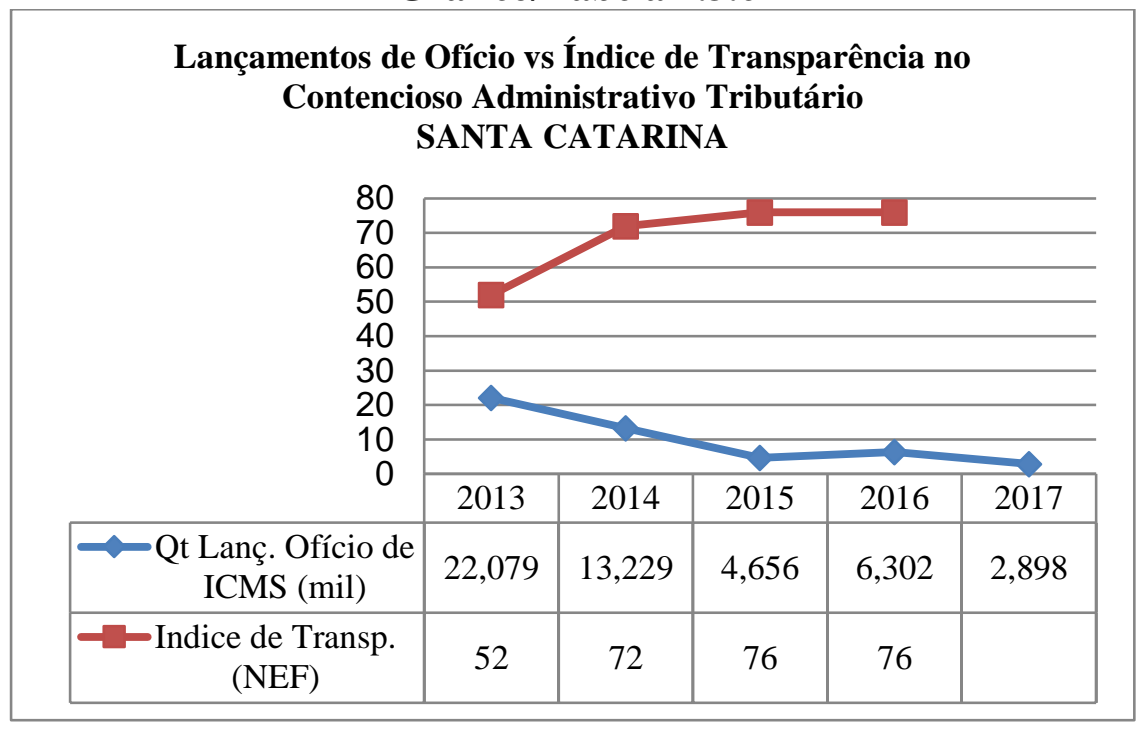

Fontes: NEF/FGV-SP e Secretaria de Estado de Fazenda de Santa Catarina. 


\section{Gráfico/Tabela 2.3.d}

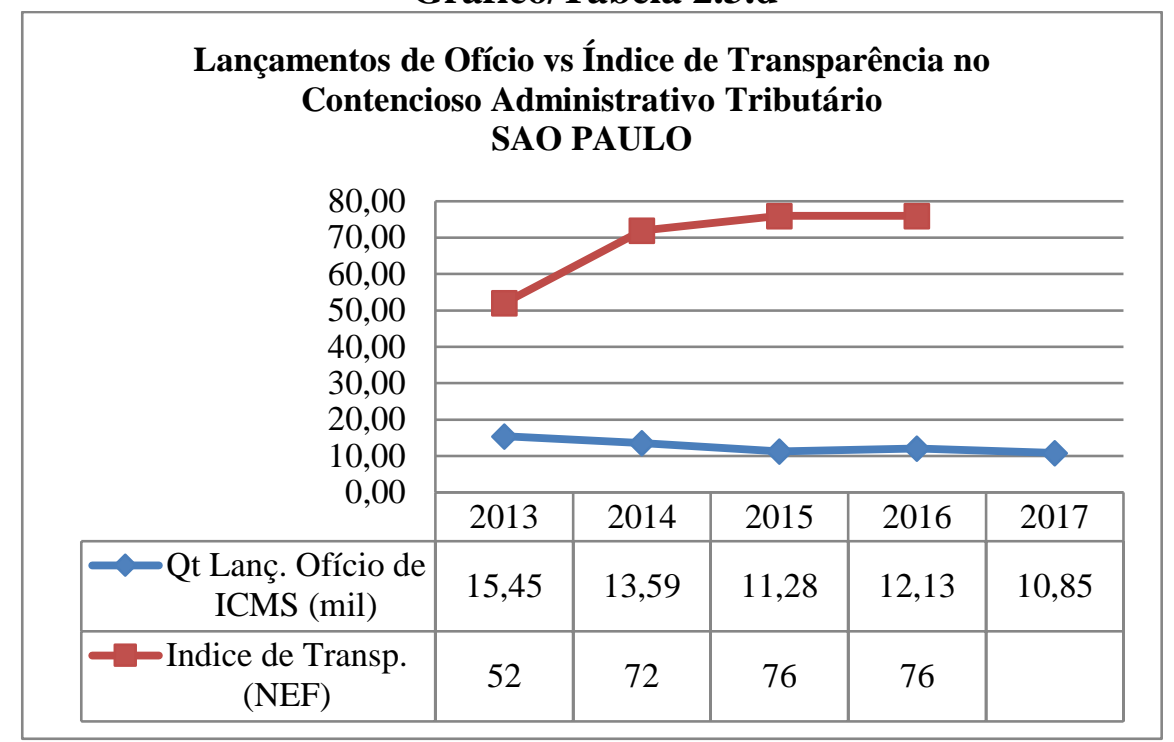

Fontes: NEF/FGV-SP e Secretaria de Estado de Fazenda de São Paulo.

Salvo o Fisco de Pernambuco, os demais analisados (PR, SC e SP), quando houve aumento no índice de transparência do contencioso tributário, houve considerável redução das quantidades de lançamentos de ofício. A reação diversa de Pernambuco pode ter ocorrido por vários motivos que demandam mais estudos.

O interessante é a semelhança de reação entre os três Fiscos estaduais: o mesmo efeito espelho ao da análise do Fisco Federal, do subcapítulo anterior.

Realizaram-se outras comparações quanto à variação do volume de aplicação de multas e a média de créditos tributários constituídos por lançamento com os índices de transparência do contencioso administrativo:

\section{Gráfico/Tabela 2.3.e}

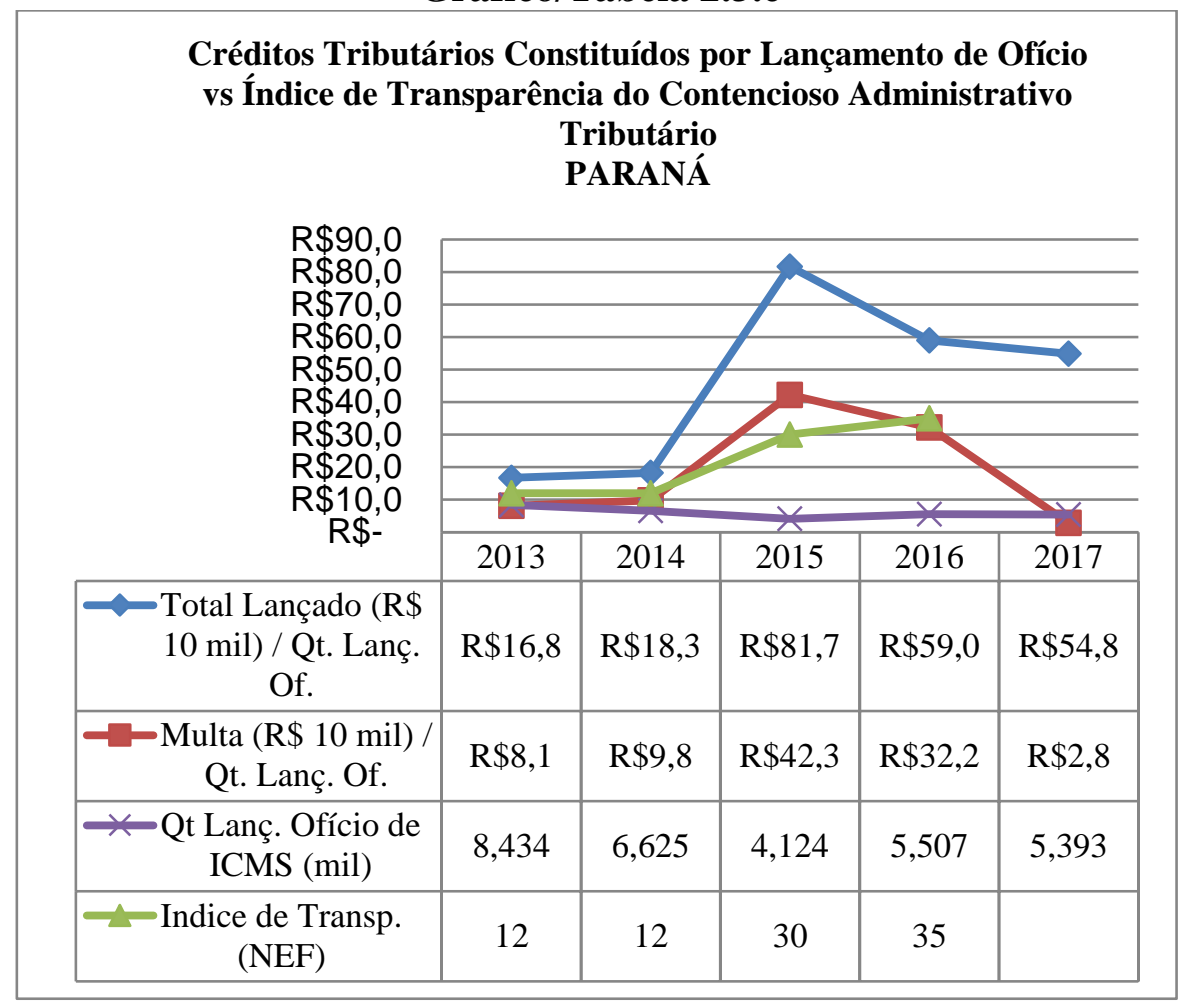

Fontes: NEF/FGV-SP e Secretaria de Estado de Fazenda do Paraná. 


\section{Gráfico/Tabela 2.3.f}

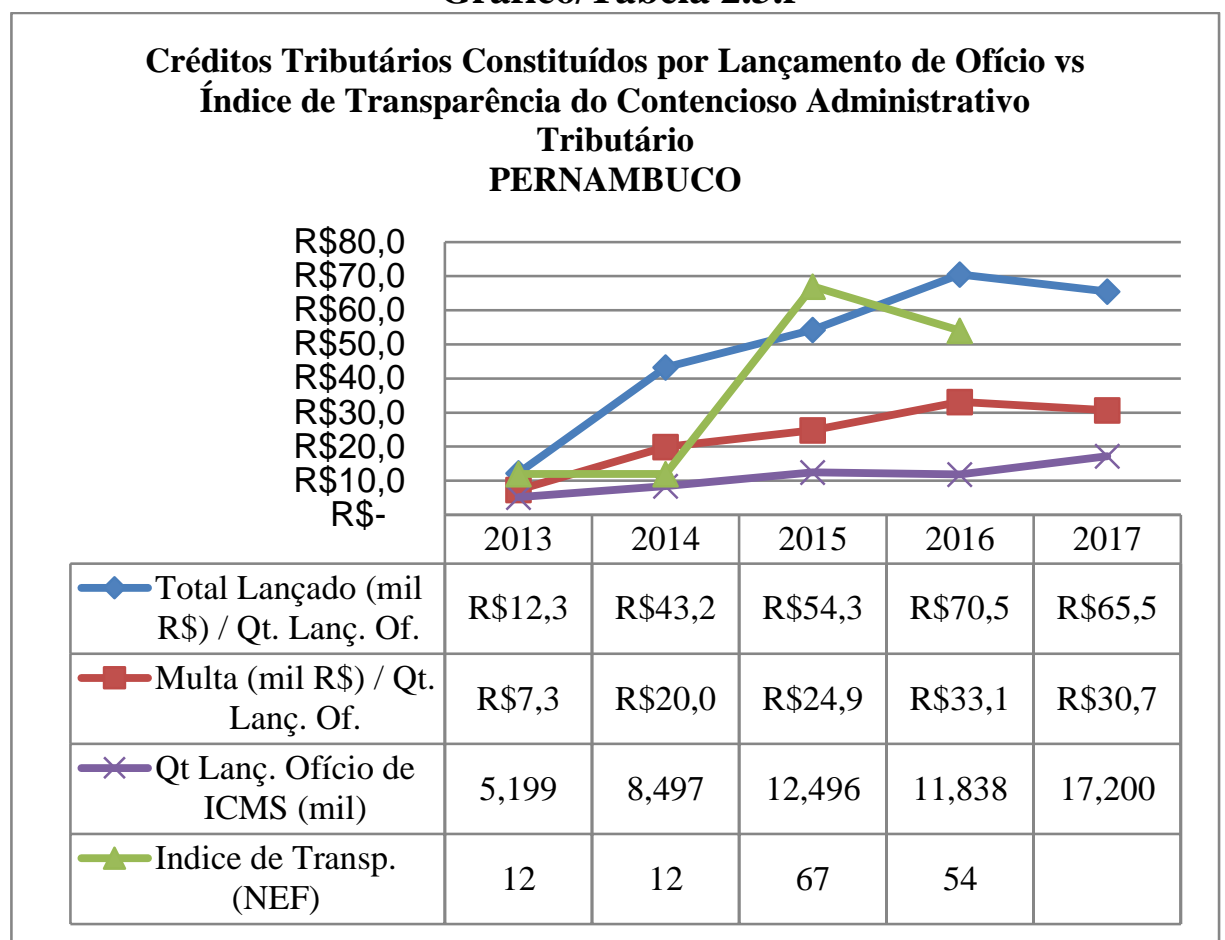

Fontes: NEF/FGV-SP e Secretaria de Estado de Fazenda de Pernambuco.

\section{Gráfico/Tabela 2.3.g}

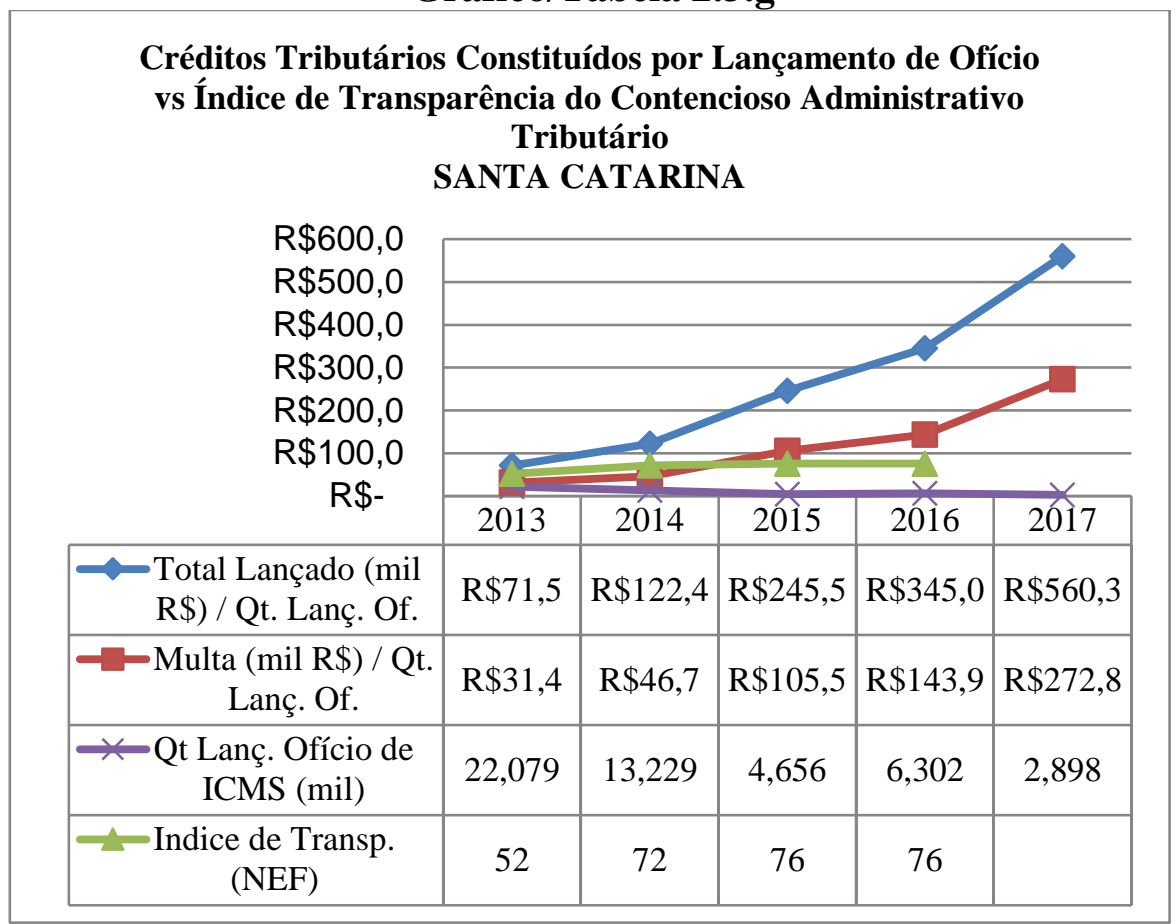

Fontes: NEF/FGV-SP e Secretaria de Estado de Fazenda de Santa Catarina. 


\section{Gráfico/Tabela 2.3.h}

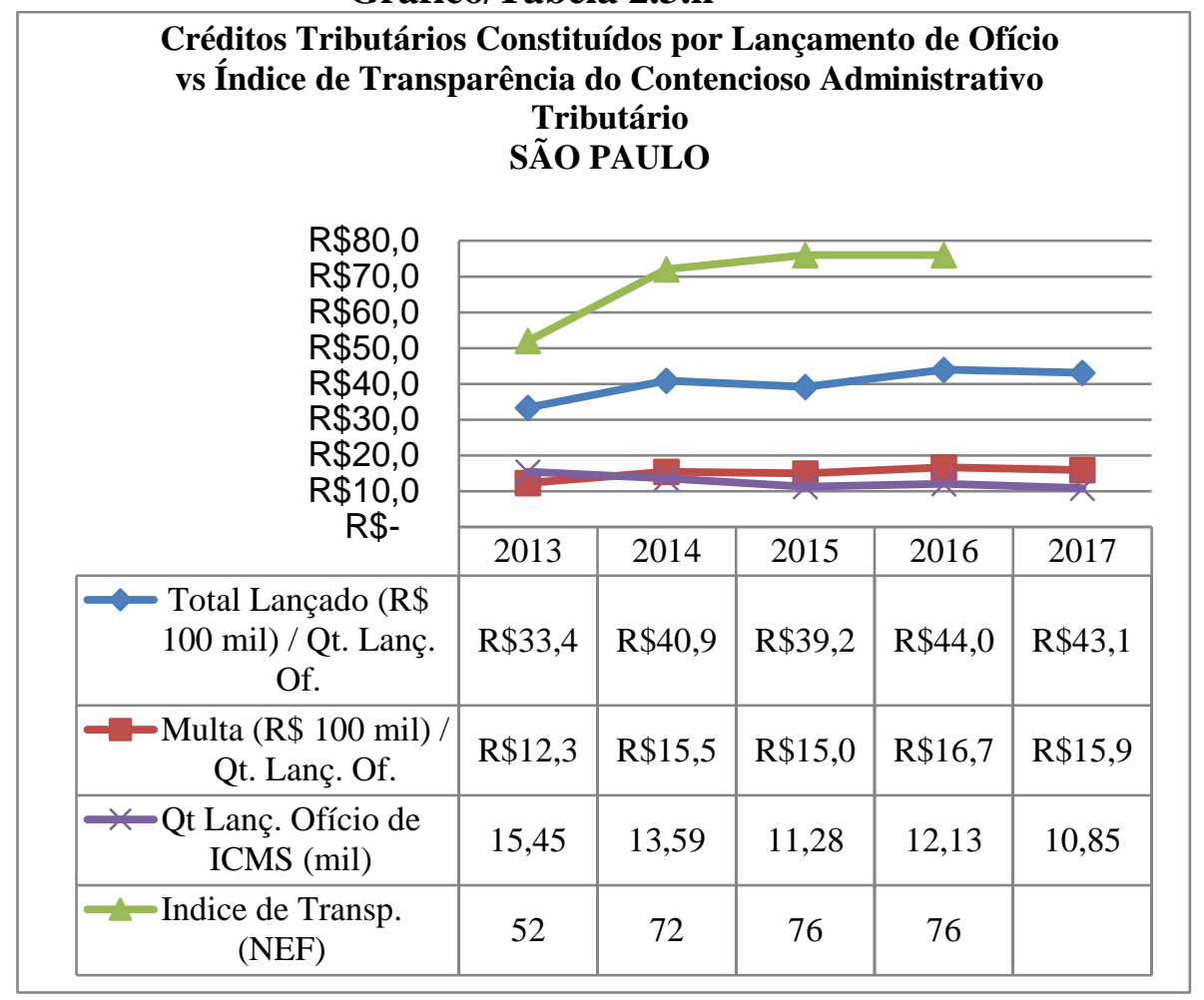

Fontes: NEF/FGV-SP e Secretaria de Estado de Fazenda de São Paulo.

Em complementação à análise anterior, verifica-se que, salvo o Fisco de São Paulo, com o aumento de transparência, houve um claro aumento dos valores de créditos tributários constituídos por unidade de lançamento tributário. O fisco paulista teve uma estabilização quanto aos valores lançados.

Deve-se considerar que os valores cedidos são nominais, contudo a variação do total dos créditos tributários constituídos por lançamento de ofício, entre 2013 e 2017, que calcula-se a porcentagem de agregação do valor do último período(2013) em relação ao primeiro(2017), foi para cada Estado o seguinte: (1) Paraná: 227,35\%; (2) Pernambuco: 433,11\%; (3) Santa Catarina: 683,24\%; (4) São Paulo: 29,02\%. Todos superiores à variação da inflação do mesmo período pelo IGP-M, aproximadamente: 28\% (FGV-IBRE, 2019).

\subsection{Observações quanto às análises de dados de lançamentos de ofício e transparência tributária}

A primeira observação da análise dos números fornecidos pelos Fiscos é a diminuição de procedimentos de lançamento de ofícios em relação ao aumento dos índices de transparência do contencioso administrativo-tributário. E, no caso dos Estados, houve a constituição com valores substancialmente maiores por lançamento quando houve patamares maiores de transparência do contencioso administrativo. O que pode indicar uma racionalização dos atos administrativos, inclusive como impacto do próprio aumento da transparência. Ou seja, a transparência tributária não afetaria apenas a ótima alocação de recursos do contribuinte, mas também da própria Administração Tributária: menor necessidade de atos para constituição de créditos tributários de maior vulto. Isso talvez se dê mediante aumento na eficiência dos trâmites arrecadatórios, o que pode representar menor alocação de recurso (procedimentos de constituição) para um aumento de valores constituídos. 
Da mesma forma, com a redução de lançamentos de ofício pode-se gerar uma redução de custos de transação tributários do contribuinte. Retornando ao início, a escolha por utilização do quantitativo de lançamentos de ofício como medida está justamente por representar o erro ou dúvida de interpretação do sujeito passivo quanto à interpretação da legislação tributária. Normalmente, cada lançamento de ofício (auto de infração) é direcionado a um contribuinte, logo, é permitido dizer que um menor número de contribuintes "errou" ao interpretar e aplicar a norma tributária, nos casos em que houve aumento da transparência do contencioso tributário. Isso, observando que a transparência do contencioso administrativo tributário, que é apenas uma parcela (apesar de significativa) da transparência tributária. Com a facilidade de busca e compreensão, os custos de transação vinculados à informação tributária são reduzidos, bem como os custos de decisão de um maior número de contribuintes em especial a posteriori (além do lançamento de penalidades, há custos consideráveis com a defesa).

Ainda, sob o olhar da preferência do contribuinte (maximização da economia tributária), ela também é atingida quando há menores penalidades às decisões tomadas, o que é permitido quando há conhecimento do ambiente institucional para previsão das possíveis consequências. ${ }^{4}$

Não se considera que os dados ora analisados sirvam de confirmação plena da hipótese da existência de relação entre transparência tributária e eficiência arrecadatória, porque a amostragem realizada foi pequena e por ausência de uma longa série histórica de índices de transparência. Todavia, eles servem de fortalecimento dos indícios e entendimentos anteriores que indicam essa relação. Também, reforça-se o entendimento de que existe relação de transparência tributária em alguma proporção com três importantes efeitos sociais já tratados por outros autores:

(a) efetivo espaço de compreensão e eficiência para defesa do contribuinte em face de quaisquer lançamentos tributários;

(b) uniformidade de entendimento das autoridades fiscais, quanto à aplicação da norma tributária;

(c) ocorrência de julgamentos céleres e fundamentados por parte das autoridades julgadoras (HIRATA, 2010).

Por consequência, criar-se-á um ambiente de clareza e previsibilidade da interpretação da norma tributária (segurança jurídica) e, talvez, menor contenciosidade na relação Estadocontribuinte, geradora natural de eficiência arrecadatória, menos custosa aos cofres públicos e menos traumática ao contribuinte e sua relação com o Estado.

Ainda, as comparações feitas permitem levantar indícios de que, quanto maior a transparência tributária, menor é a necessidade de procedimentos de lançamento tributário efetuados por agentes fiscais. Talvez, porque permita ao contribuinte ter melhor vislumbre das consequências de seus atos, permitindo melhores condições de decisão, e um maior volume de adesão voluntária, sem aumento dos custos do Estado. E permita a fiscalização concentrar-se em contribuintes com maiores volumes de descumprimento, com menor número de procedimentos. De qualquer forma, a análise dos dados gerou a conclusão de que existem indícios que levam a crer que existe relação entre transparência tributária e eficiência arrecadatória.

\section{CONCLUSÃO}

Os elementos que subsidiam as conclusões são de ordem bibliográfica e empírica. Os quais alguns de seus principais pontos são retomados, chegando da confirmação, pelo menos parcial, das hipóteses principal considerando conjunto dos elementos do estudo.

\footnotetext{
${ }^{4}$ Sob a ótica de conformidade tributária e competitividade, o trazido coaduna ao entendimento de Eric. A. Posner, o qual reflete sobre a clareza dos entendimentos normativos da Administração Pública como um dos fatores que estimulam o compliance tributário dos contribuintes, justamente por gerar um ambiente de menor diferenciação competitiva com base na aplicação legal indevida, evitando essa externalidade negativa (POSNER, 2000).
}

Revista de Direito Brasileira | Florianópolis, SC | v. 27 | n. 10 | p.92-111 | Set./Dez. 2020 
Como forma de estabelecer uma concepção dos elementos trabalhados, considerou-se que eficiência é a melhor alocação de recursos (custos) para maximização dos resultados (bens/dinheiro/utilidade), a transparência vincula-se ao elemento de recursos afetando a eficiência. Como a eficiência pode ser encarada como um valor (princípio), o conteúdo deontológico dela será a observação justamente dos custos, logo, da eficiência. Isso denota que transparência tributária influencia diretamente no custo de transação do mercado, tanto por parte do contribuinte quanto do Fisco.

Entretanto, de forma quase endêmica, em todas as unidades federativas brasileiras, existem normas procedimentais avessas à transparência tributária, utilização de expedientes obscuros, por exemplo: a não disponibilização do conteúdo normativo de suas decisões administrativas ou a vedação de acesso dos contribuintes aos procedimentos administrativos. Podese afirmar que se trata de opacidade deliberada por parte das Administrações Tributárias e do próprio contribuinte, o dificultam ou não permitem a aferição clara dos efeitos da transparência a contento.

Com a observação dos de custos de arrecadação entre o Fisco e contribuinte, inclusive com as transferências de ônus, riscos e custos a este último, em especial nos casos de constituição do crédito tributário por autolançamento, chega-se a apontar o contribuinte é o principal intérprete da norma tributária. E em razão disso, o custo de arrecadação decorrente dos custos de oportunidade, informação e decisão é intimamente vinculado à relação de transparência/opacidade tributária. Tanto que, em ambientes institucionais opacos, permite-se a criação de falhas de mercado e estímulos a não cooperação, as quais aumentam os custos de arrecadação arcados tanto pelo Fisco quanto pelo Contribuinte (custo de conformidade).

A preferências de decisão contribuintes (economia tributária) e agentes fiscais (eficácia de arrecadação) apesar de distintas, dependem da otimização de recursos. Portanto, como transparência tributária atinge diretamente nos custos de arrecadação (tanto do Fisco como do contribuinte), ela influenciará nas preferências e tomada de decisões do contribuinte e dos agentes fiscais.

Assim, há a importância de observação dos lançamentos tributários de ofício em relação de parcelas auferíveis da transparência tributária (índice de transparência do contencioso tributário). O cruzamento dos dados de volumes de lançamentos tributários com índice de transparência do contencioso administrativo tributário permitiu vislumbrar que há relacionamentos entre quantidades/valores individuais de lançamentos e a transparência do contencioso, o que alteraria a qualidade da atuação tributária. Isso porque, entre outras situações, permite ao contribuinte evitar ou rever erros na interpretação da norma tributária com menor custo de conformidade, bem como pode gerar ao Fisco a otimização de procedimentos.

Dentre os pontos que não puderam ser verificados, o mais importante é a impossibilidade de quantificação clara do relacionamento entre transparência tributária e eficiência arrecadatória, por vários motivos, ausência de meios de aferição e, em especial, não compilação ou fornecimento de dados suficientes por parte das Administrações Tributárias brasileiras.

Assim, a pesquisa ora apresentada resumidamente alcançou seus objetivos:

a) confirmando que aplicação da transparência tributária afeta a constituição do crédito tributário e os custos de conformidade do contribuinte (e de arrecadação);

b) indicando indícios para confirmar a existência de relação entre a transparência tributária e a eficiência arrecadatória.

\section{REFERÊNCIAS}

AFONSO, José Roberto Rodrigues; FUCK, Luciano Felício; CORREA NETO, Celso de Barros; SZELBRACIKOWKI, Daniel Correa. Guerra Fiscal do ICMS: Organizar o desembarque. 
Revista de Direito Internacional Econômico e Tributário, v. 12, n. 1, 2017. Disponível em: <http://bit.ly/2y0C7NM>. Acesso em: 7 dez. 2017.

AFONSO, José Roberto Rodrigues; CASTRO, Kleber. Termômetro tributário no Brasil em 2016: recuperação na reta final, mas com receitas atípicas. IDP - Caderno Virtual, Brasília, 2017.

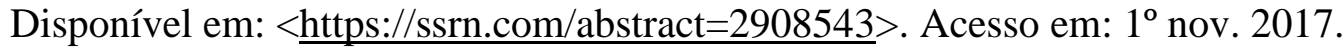

ALMEIDA, Carlos Otávio Ferreira de. Notas sobre litigiosidade tributária e compliance cooperativo no Brasil. Revista de Direito Tributário Atual. São Paulo: Instituto Brasileiro de Direito Tributário, v. 40, dez. 2018.

BERTOLUCCI, A.; NASCIMENTO, D. O custo de arrecadação de tributos federais. Revista Contabilidade \& Finanças, v. 17, n. esp., ago. 2006. Disponível em:

<http://www.revistas.usp.br/rcf/article/view/34194>. Acesso em: 30 mar. 2019.

BIRD, Richard. Smart tax administration. Economic Premise. Washington: The World Bank, n. 36, out. 2010. Disponível em:

<http://siteresources.worldbank.org/INTPREMNET/Resources/EP36.pdf>. Acesso em: 11 abr. 2018.

BRASIL. Subsecretaria de Fiscalização da Secretaria da Receita Federal do Brasil. Plano anual da fiscalização da receita federal do brasil 2015 e resultados de 2014. 2015. Disponível em: <http://idg.receita.fazenda.gov.br/dados/resultados/fiscalizacao/arquivos-e-imagens /2015_03_05-plano-anual-da-fiscalizacao-2015-e-resultados-2014.pdf/view>. Acesso em: 4 dez. 2017.

BRASIL. Subsecretaria de Fiscalização da Secretaria da Receita Federal do Brasil. Plano anual da fiscalização da receita federal do brasil 2017 e resultados de 2016. 2017. Disponível em: <http://idg.receita.fazenda.gov.br/dados/resultados/fiscalizacao/arquivos-e-imagens /plano-anualde-fiscalizacao-2017-e-resultados-2016.pdf/view>. Acesso em: 4 dez. 2017.

BUCHANAN, James M. Cost and choice: an inquiry in economic theory. Indianapolis: Liberty Fund, 1999. Disponível em: 〈http://files.libertyfund.org/files/1068/0102-06_LFeBk.pdf>. Acesso em: 24 abr. 2019.

CALIENDO, Paulo. Direito tributário e análise econômica do direito: uma visão crítica. Rio de Janeiro: Elsevier, 2009.

CALIENDO, Paulo. Direito Tributário e análise econômica do Direito: contribuições e limites. Revista da FESDT. Porto Alegre, n. 3, jan./jun. 2009.

CARCOVA, Carlos Maria. A opacidade do direito. Trad. Edilson Alkmim Cunha. São Paulo: LTr, 1998.

CARVALHO, Cristiano. Teoria da decisão tributária. São Paulo: Saraiva, 2018.

CARVALHO, Cristiano. A Tributação Estratégica. Introdução à teoria dos jogos no direito Tributário. Direito Tributário Atual. São Paulo: IBDT, v. 1, 2014. Disponível em: <http://works.bepress.com/cristiano_carvalho/31 >. Acesso em: 12 abr. 2018. 
CARVALHO, Paulo Barros de. Curso de direito tributário. 13 ed. São Paulo: Saraiva, 2000.

CARVALHO, Paulo Barros de (Coord.). BRITO, Lucas Galvão de (Org.); DIAS, Karem Lureidini (Org.); AGUIAR, Luciana Ibiapina Lira. Compliance e a implementação de deveres instrumentais. Compliance no direito tributário. São Paulo: Revista dos Tribunais, 2018.

CENTRO INTERAMERICANO DE ADMINISTRAÇÕES TRIBUTÁRIAS (CIAT). Transparência e prestação de contas. Madri: CIAT, 2018. Disponível em: <https://ciatorg.sharepoint.com/sites/cds/Conocimientos/Redes/ComiteEtica/2018_Transparenci a_AT_pt.pdf?slrid=4646879e-006b-6000-d1b5-33c788b9ecc1>. Acesso em: 9 jul. 2018.

COASE, Ronald Harry. A firma, o mercado e o direito. 2 ed. Trad. Heloisa Gonçalves Barbosa. Rio de Janeiro: Forense Universitária, 2017.

COELHO, Isaías (Coord.); CORRÊA, André Rodrigues (Coord.); SANTI, Eurico de (Coord.). $4^{\mathrm{a}}$ aferição da transparência do contencioso administrativo tributário - ICAT 2016. São Paulo: FGV Direito SP, 2017. Disponível em:

<https://direitosp.fgv.br/sites/direitosp.fgv.br/files/arquivos/relatorio_final 4o_afericao_do_icat $\underline{0 . p d f>}$. Acesso em: 10 set. 2017.

ENGISCH, Karl. Introdução ao pensamento jurídico. Trad. João Baptista Machado. Lisboa: Fundação Calouste Gulbenkian, 2001.

FUNDAÇÃO GETÚLIO VARGAS - INSTITUTO BRASILEIRO DE ECONOMIA (FGVIBRE).Fgvdados. 2019. Disponível em 〈http://www14.fgv.br/fgvdados20/consulta.aspx $>$. Acesso em 20 abr. 2019.

HÄBERLE, Peter. Hermenêutica constitucional, a sociedade aberta dos intérpretes da constituição: contribuição para a interpretação pluralista e procedimental da constituição. Trad. Gilmar Ferreira Mendes. Porto Alegre: Sérgio Antônio Fabris Editor, 1997.

HIRATA, Dalton Yoshio. Processo Administrativo Fiscal: Melhorar e Unificar a Legislação sobre os Procedimentos? Blog do NEF, Núcleo de Estudos Fiscais da FGV/SP, São Paulo, 29 set. 2010. Disponível em: <http://estudosfiscais.blogspot.com.br/2010/09/processo-administrativofiscal-melhorar.html>. Acesso em: 10 out. 2016.

LOPES, Maurício Antônio Ribeiro. Comentários à reforma administrativa: de acordo com as emendas constitucionais 18, de 05.02.1998, e 19, de 04.06.1998. São Paulo: Revista dos Tribunais, 1998.

MARTINS, Ives Gandra da Silva (Coord.). Teoria da imposição tributária. Curso de direito tributário. São Paulo: Saraiva, 2008.

ORGANIZAÇÃO PARA A COOPERAÇÃO E DESENVOLVIMENTO ECONÔMICO (OCDE). Centre for Tax Policy and Administration. Tackling Aggressive Tax Planning through improved transparency and disclousure. Paris: OCDE, 2011. Disponível em: <http://www.oecd.org/ctp/exchange-of-tax-information/tacklingaggressivetaxplanningthrough improvedtransparencyanddisclosure.htm>. Acesso em: 20 jun. 2018. 
POSNER, Eric A. Law and social norms: the case of tax compliance. Virgínia Law Review, v. 86, 2000 .

POSNER, Richard A.. El análisis económico del derecho. 2 ed. Trad. Eduardo L. Suárez. México: Fondo de Cultura Económica, 2007.

POSNER, Richard A.. Problemas da filosofia do direito. Trad. Jeferson Luiz Camargo. São Paulo: Martins Fontes, 2007.

PIMENTEL, Mariana. Por que contribuintes cumprem normas tributárias. Blog do NEF. Núcleo de Estudos Fiscais da FGV Direito, São Paulo, 11 ago. 2010. Disponível em: <http://estudosfiscais.blogspot.com.br/2010/08/por-que-contribuintes-cumprem-normas.html>. Acesso em: 20 out. 2016.

SANTI, Eurico Marcos Diniz de. Kafka, alienação e deformidade da legalidade, exercício do controle social rumo à cidadania fiscal. São Paulo: Revista dos Tribunais; Fiscosoft, 2014.

SANTI, Eurico Marcos Diniz de. Reforma do ICMS no Mato Grosso: paradigma da legalidade nacional. Jota info. Brasília: Jota, 06.11.2016. Disponível em: <https:/www.jota.info/opiniao-eanalise/artigos/reforma-icms-no-mato-grosso-paradigma-da-legalidade-nacional-06112016>. Acesso em: 16 mar. 2019.

STIGLITZ, Joseph E. On liberty, the right to know, and public discourse: the role of transparency in public life. Oxford: Oxford Amnestry Lecture, jan. 1999. Disponível em:

$\langle$ http://citeseerx.ist.psu.edu/viewdoc/download?doi=10.1.1.594.93\&rep=rep1\&type=pdf $>$. Acesso em: 20 mar. 2019.

SOUZA, Antônio Francisco de; BRANCO, Paulo Gonet (Coord.); MEIRA, Liziane Angelotti (Coord.); CORREA NETO, Celso de Barros (Coord.) et al. Garantias fundamentais de segurança jurídica no procedimento tributário. In: Tributação e direitos fundamentais: conforme a jurisprudência do STF e STJ. São Paulo: Saraiva/IDP, 2012. 